\title{
De la Música en Els Joglars: Columbi Lapsus
}

\author{
On the music in Els Joglars: Columbi Lapsus
}

\begin{abstract}
Anna Corral Fullà
Universitat Autònoma de Barcelona, Departament de Filologia Francesa i Romànica, Barcelona, España. Correo electrónico: ana.corral@uab.cat
\end{abstract}

Este artículo se propone analizar uno de los recursos expresivos de mayor relieve en la producción teatral de Els Joglars, la música, cuyo peso ha sido y continúa siendo capital en la construcción y montaje de todo su repertorio. Para ello, hemos tomado como botón de muestra el espectáculo Columbi Lapsus (1989), una obra peculiar en su concepción. Construida en forma de ópera, la música asume igualmente muy diversas funciones en el espectáculo. A lo largo de este estudio, seremos testigos de la multiplicidad de voces que se entrecruzan en esta obra singular en la que el sonido se erige en elemento clave para la construcción de la trama y para todo aquel receptor que desee desenredar adecuadamente la madeja.

Palabras clave: teatro, Els Joglars, Columbi Lapsus, música, Rossini.

This paper aims to analyse one of the most remarkable expressive resources in the theatre production of Els Joglars: music, whose prevalence has been and continues to be central to the production and staging of its entire repertoire. We will illustrate this point through the show Columbi Lapsus (1989), a piece unique in its conception. Written in the form of opera, the music also takes on a wide range of roles in the show. By way of this study, we will be witnesses to the multiplicity of voices that intertwine in this singular production. Here, sound comes to the fore as a key element for the development of the plot and for anyone who wishes to unravel the thread satisfactorily.

Key words: theatre, Els Joglars, Columbi Lapsus, music, Rossini.

\section{INTRODUCCIÓN}

En 1961, tres jóvenes del mundo teatral barcelonés -Albert Boadella, Carlota Soldevila y Antón Font- fundaron la compañía de mimo que denominaron Els Joglars. Una compañía viva y todavía vigente en la actualidad, aunque ya bastante alejada de los principios de la escuela de mimo clásico de la que partieron. En efecto, Els Joglars cuenta ya tras suyo con cincuenta años de recorrido, a lo largo de los cuales la compañía no ha parado de buscar y de ahondar en las posibilidades de los diversos lenguajes que intervienen en la creación de una obra teatral. Y en esta búsqueda han edificado una nueva manera de concebir el teatro, un lenguaje propio que los 
caracteriza y que desplegando todo un abanico de recursos ha integrado de forma gradual desde la expresión corporal, cada vez más elaborada y perfeccionada, hasta la incorporación de otros lenguajes artísticos en su teatro -danza, palabra y música-.

Este artículo se propone analizar uno de los recursos expresivos de mayor relieve en la producción teatral de Els Joglars, la música, cuyo peso ha sido y continúa siendo capital en la construcción y montaje de todo su repertorio. Para ello, centraremos nuestra atención en una de sus producciones, Columbi Lapsus, una obra cuya "trama no obedecía ni a un drama, ni a una farsa. El tono adecuado era el de un libreto de ópera” (Ribas 1989).

\section{OBERTURA}

Columbi Lapsus se estrenó en noviembre de 1989 en el Teatro Municipal de Gerona. La temática de la obra se centra en el corto mandato del papa Juan Pablo I y en las extrañas circunstancias que rodearon su muerte, ahondando en las intrigas, intereses y tejemanejes de la Curia Vaticana. Esta temática permitirá a la compañía tratar una de las cuestiones más defendidas por Albert Boadella: la incompatibilidad del poder con la personalidad de un "hombre sencillo, honrado e inteligente" (Pérez de Oleguer 1989). Albert Boadella ha declarado: "Si adoptas esta postura de, al fin y al cabo, honradez intransigente, acabas con la dimisión o la muerte, y como un Papa no tiene la primera posibilidad, no puede salir por la puerta de detrás del Vaticano, se va a los subterráneos con los pies por delante” (Fondevila 1989b: 8; traducción de la autora).

Columbi Lapsus es una obra de gran delicadeza y sobriedad, cuestión quizá determinada, en parte, por su temática, pero ante todo por la elegancia en su tratamiento dramatúrgico y escénico. De ese modo, en el espectáculo, se hace uso de una parodia sosegada con "más sonrisas y menos carcajadas, más sutileza y menos provocación” (Arco 1989) y “menos preocupada en hacer reír en todo instante y, por lo mismo, más verdadera, más creíble y más cercana” (Monleón 1990). Esa “sátira en sordina”, como le ha dado en llamarla Abellán (2001: 102-09), va acompañada de un acercamiento al personaje papal en extremo respetuoso, el cual nos es presentado en toda su dimensión humana y afectiva.

Columbi Lapsus es una obra discreta desde todos sus ángulos. El espectáculo parte de una gran austeridad escenográfica; unos lienzos de Miguel Ángel y una alfombra delimitan el escenario en el que "los mismos actores a través de sus acciones, y ayudados por una ajustada iluminación, van creando los diferentes espacios del Vaticano” (Pérez de Oleguer 1989). La moderación en Columbi Lapsus alcanza aún otro aspecto de la puesta en escena. Su objetivo ya no es el de plantear nuevas formas escénicas experimentales, como era el caso en los espectáculos precedentes en su intento de integrar al público en la representación; Columbi Lapsus se presenta según la convención teatral y, de ese modo, Els Joglars gana, como dijera Ros Ribas, “un toque de clasicismo" (1989). La irrupción de la cuarta pared en esta producción representa el inicio de un nuevo teatro, si no más convencional, puesto que la obra hace alarde de una gran originalidad e incorpora elementos nunca antes explotados en su teatro, sí más adaptado a los cánones tradicionales.

Otra de las características más relevantes de Columbi Lapsus es su carácter foliáceo. Si bien es cierto que la obra muestra ante el gran público el corto papado de Juan Pablo I, trama que permitirá abordar la delicada cuestión sobre la incompatibilidad del 
poder con la honradez e integridad en el ser humano, el espectador se verá arrollado y en ocasiones confundido ante la presencia de géneros y manifestaciones artísticas diversas. A la presencia de los lienzos de Miguel Ángel en el decorado de la escena, lienzos que transportan al espectador a principios del siglo XVI y al Vaticano, se añade la música de la ópera El Barbero de Sevilla de Rossini, la que participa de principio a fin en el espectáculo y cuya presencia será determinante en la elaboración de la puesta en escena y de la trama. Pero aún más, ante los ojos del espectador, se desarrolla una intriga de gángsteres -burda representación de la Curia Vaticana- en la que unos personajes ataviados según las características del género representan a una banda criminal organizada, la cual no duda en poner en marcha las más viles maniobras con tal de alcanzar sus fines. Así pues, ante nosotros se encuentran tres líneas argumentales: el papado de Juan Pablo I, la fábula de Rosina y el conde Almaviva y la historia de una banda de criminales. Por momentos, el espectador creerá asistir a la representación de una ópera y escuchará las arias más preciadas de El Barbero de Sevilla, creerá estar presenciando el complot y los ardides más osados para engañar a Bartolo y sentirá ese tono jocoso de la ópera buffa, esa comedia ingenua y fresca que Rossini compuso. Pero acto seguido, ese mismo espectador se quedará atónito ante la crueldad de la mafia, aterrorizado ante la frialdad y perversidad del capo Cirkus -alusión directa al Cardenal Marcinkus-, quien calcula y, si es preciso, ejecuta. Y ya no escuchará una ópera de alegres arias y temática burlesca, sino que se verá inmerso en "un argumento que bien pudiera haberse extraído de una película de cine negro" (Altarriba 1989; traducción de la autora). Luego, aparecerá en escena el personaje del Albíssimo -encarnación del Papa Juan Pablo I-, su bondad e ingenuidad, su paciencia, sus maneras suaves y parsimoniosas. Y de nuevo se encontrará sumido en esa época de un papado prometedor que se reveló imposible, incapaz de luchar contra los intereses creados. Tres argumentos que se entrecruzan, alimentándose uno al otro, confiriendo una densidad y profundidad sin igual al espectáculo, creando un tupido palimpsesto cuyo resultado dará esta obra admirable, capaz de transportar al espectador desde la sonrisa cómplice al recelo, y de la desconfianza a la ternura y el reconocimiento.

De entre ese entresijo de diversas manifestaciones artísticas, la música representa el núcleo a partir del cual se desplegarán todos los otros recursos expresivos en el espectáculo desde su misma génesis. La ópera de Rossini, con sus peculiares características y estilo musical, representará un fabuloso e inagotable manantial para la puesta en escena: reproducción de fragmentos, imitación de modelos, intervención en la trama. En apartados posteriores, nos será posible ahondar en el papel que juega esta célebre ópera de Rossini en Columbi Lapsus, un papel preponderante y crucial sin lugar a dudas.

\section{ATTO PRIMO: MACRO Y MICRO ESTRUCTURA EN COLUMBI LAPSUS, UNA OBRA EN FORMA DE ÓPERA}

Columbi Lapsus, en su construcción, toma como punto de partida la ópera bufa de Rossini El Barbero de Sevilla. La temática de la producción teatral de Els Joglars, situada en el Vaticano y cuyo objetivo es el de reflejar su estructura y funcionamiento en un momento histórico concreto, encuentra en esta ópera similitudes tanto argumentales como formales que se adaptan perfectamente al objetivo dramatúrgico 
perseguido en Columbi Lapsus. Si la estructura vaticana nos es presentada como una banda de mafiosos, en el Barbero de Sevilla asistimos igualmente a los complots y ardides llevados a cabo por el decrépito Don Bartolo para conseguir casarse de forma forzada y deshonrosa con la joven Rosina, enamorada del Conde Almaviva. En ambas obras, las intrigas y viles maniobras juegan un papel esencial en la trama, lo cual permite a Els Joglars apropiarse de algunas arias de la ópera que se ajustan por su contenido al desarrollo de la acción presentada en su espectáculo. Muchos son los ejemplos que dan fe de ello, quizá la escena de "La Calumnia” es la más representativa al abarcar íntegramente el cuarto cuadro del primer acto en su totalidad. Por otra parte, si Columbi Lapsus es una obra sobria, no por ello se deja de recurrir a la parodia y la sátira habituales en el teatro de la compañía. El Barbero de Sevilla es, a su vez, una ópera bufa en la que se explota al máximo la comicidad de las diversas situaciones y embrollos que se van sucediendo sobre el escenario. Ese tono jocoso de la ópera no tan sólo se adapta al estilo humorístico de Els Joglars, sino que será esgrimido de forma recurrente en Columbi Lapsus. Por último, la utilización de la ópera no es en modo alguno un elemento externo que pudiera romper la verosimilitud del espectáculo, sino más bien un dispositivo que se integra perfectamente en el contexto situacional de la obra: "no hay que olvidar que la mafia es altamente amateur de las óperas” (entrevista con Boadella en 2008). Si todo este conjunto forma un núcleo bien homogéneo y otorga solidez a la obra, ello no hubiera sido posible sin un minúsculo pero esencial matiz que colorea el discurso de los personajes. En efecto, tanto la temática de la obra, situada en el Vaticano, como la utilización de la ópera de Rossini, hicieron necesario el uso de la lengua italiana en Columbi Lapsus. Como Boadella explica "no lo podíamos hacer ni en catalán ni en castellano sino que, si queríamos estar en el juego general, teníamos que hacerlo en italiano” (entrevista con Boadella en 2008), un italiano "macarrónico”, como lo define Mercè Saumell (251), con el objetivo de facilitar al público su comprensión.

Es curioso observar la similitud existente en la forma artesanal de trabajar de la compañía Els Joglars y la de los compositores coetáneos de Rossini. Roger Alier, en una de sus charlas con Gorgori en torno a la figura de Rossini, comparaba su forma de abordar la composición al trabajo de un sastre: "Un sastre tiene un cajón con botones, con retazos de chaleco, con mangas de varios colores, con hilos... ¡Y si lo necesita, mezcla todo eso y confecciona una nueva obra!” (Alier 132). La compañía de Els Joglars procede de forma similar, aprovecha obras de arte ya existentes y las pone al servicio de sus necesidades creativas. Para ello, música de grandes compositores, lienzos de pintores reputados, fragmentos de textos dramatúrgicos de otros autores, literatura, cine, todo a disposición de una obra nueva e inédita. Y de este modo, en Columbi Lapsus, Els Joglars recoge la ópera de Rossini transformándola y adaptándola a su espectáculo como el mismo Rossini hubiera podido hacer en su época.

Columbi Lapsus está estructurada en forma de ópera y con el molde de la composición El Barbero de Sevilla, aunque reestructurando y reelaborando el material musical impreso. Boadella hace una selección de las arias, toma los fragmentos que convienen para cada escena y la trama de la obra y los reordena. Si se compara la estructura de la ópera y la obra de Els Joglars, así como la disposición de los diferentes fragmentos musicales que en ella aparecen, se puede observar que, si la macroestructura en general se mantiene, se producen variaciones en cuanto a la selección de las arias y la ordenación de éstas en el conjunto de la obra. Veamos el siguiente cuadro: 
Cuadro 1. Comparación entre la estructura de la ópera de Rossini y la obra de Els Joglar

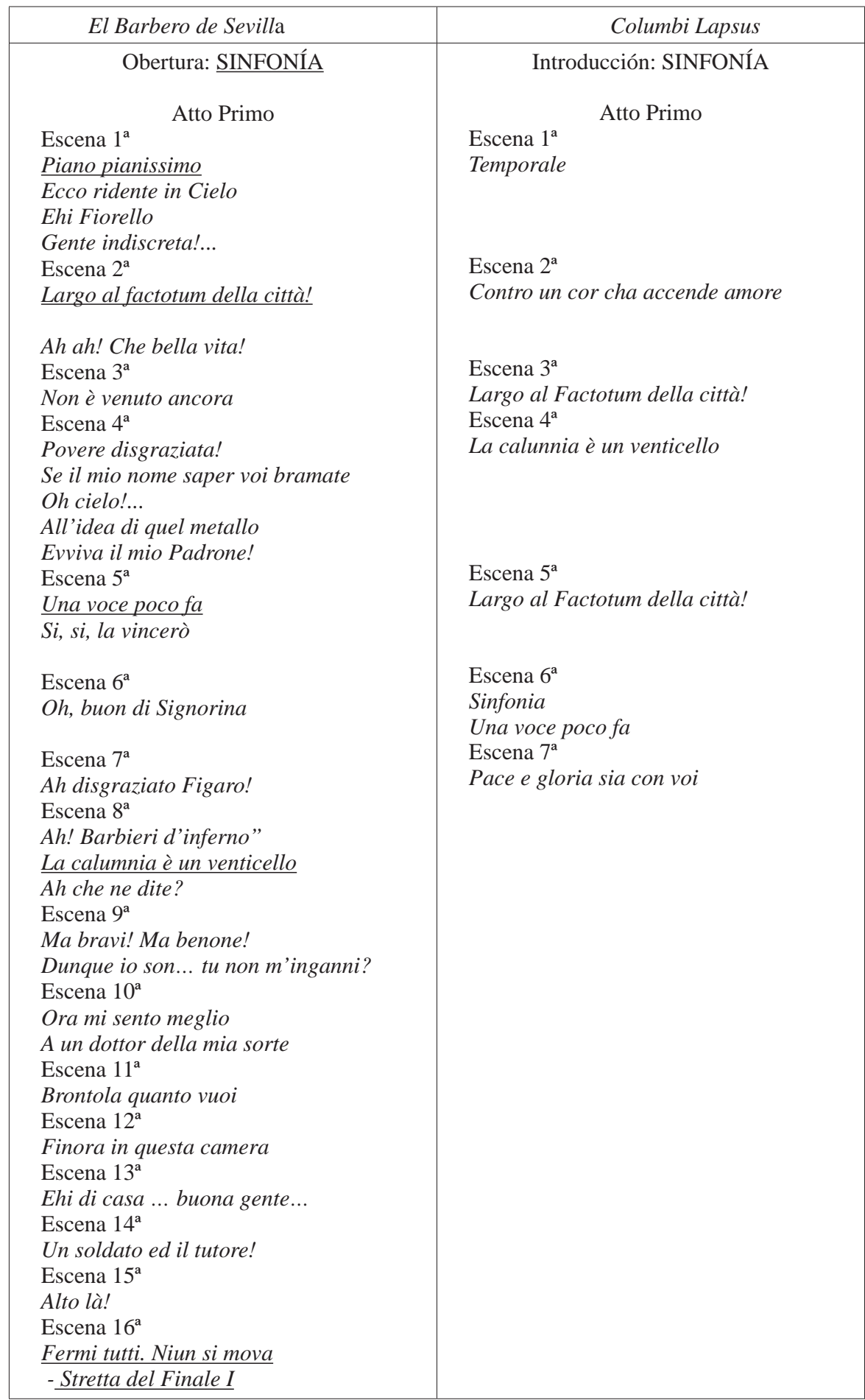


El Barbero de Sevilla

\section{Atto Secondo}

Escena $1^{\mathrm{a}}$

Ma vedi il mio destino!

Escena $2^{\mathrm{a}}$

Pace e gloria sia con voi

Insomna, mio signore

\section{Escena $3^{\mathrm{a}}$}

Venite, signorina

Contro un cor che accende amore

Bella voce! Bravissima

Quando mi sei vicina

Bravo, signor barbieri

Escena $4^{\mathrm{a}}$

Don Basilio!

\section{Escena $5^{\mathrm{a}}$}

Ah, disgraziato me!

Escena $6^{\mathrm{a}}$

Il vecchiotto cerca moglie

\section{Escena $7^{\mathrm{a}}$}

Dunque voi Don Alonso, non conoscete affatto?

Escena $8^{\mathrm{a}}$

Per forza o per amore

Escena $9^{\mathrm{a}}$

Temporale

Alfine eccoci qua

Ah! Qual colpo

Ah, disgraziati noi!

Escena $10^{\mathrm{a}}$

Don Bartolo, Don Bartolo

Escena $11^{\mathrm{a}}$

Il Conte! Ah, che mai sento!

Cessa di più resistere

Insomma io ho tutti i torti!

Di si felice innesto
Columbi Lapsus

Introducción: Contro un cor cha accende amore

Atto Secondo

Escena $1^{\mathrm{a}}$

Fermi tutti. Niun si mova

(Stretta del Finale I, tutti final)

Escena $2^{\mathrm{a}}$

Piano pianissimo

Ah! Qual colpo

Fermi tutti. Niun si mova

(Stretta del Finale I, tutti final)

Piano pianissimo

Contro un cor cha accende amore

Piano pianissimo

Escena $3^{\mathrm{a}}$

Una voce poco fa

Escena $4^{\mathrm{a}}$

Temporale

Fermi tutti. Niun si mova (Andante)

Largo al Factotum della città! 
Como se puede observar a partir de la tabla precedente, la macroestructura de las dos obras es muy similar. En efecto, El Barbero de Sevilla y Columbi Lapsus están organizadas en dos partes: un primer acto más extenso y un segundo acto más reducido. Si bien es cierto que la ópera posee un mayor número de escenas por acto, la proporción de escenas entre el primer y el segundo acto se mantiene no obstante en el espectáculo de Els Joglars.

Cuadro 2. Comparación en el número de actos

\begin{tabular}{|c|c|c|}
\hline Actos & El Barbero de Sevilla & Columbi Lapsus \\
\hline Atto Primo & 16 escenas & 7 escenas \\
\hline Atto Secondo & 11 escenas & 4 escenas \\
\hline
\end{tabular}

Sin embargo, también es posible apreciar algunas variaciones en la macroestructura de Columbi Lapsus. En primer lugar, se observa que, así como el primer acto se abre en ambas producciones con una obertura -la sinfonía-, en la obra de Els Joglars, el segundo acto se introduce igualmente con un fragmento musical -el aria para mezzosoprano Contro un cor cha accende amore- que ejerce la misma función que la Sinfonía del inicio: una introducción a la segunda parte de la obra de la que la ópera carece. Por otra parte, el espectáculo de Els Joglars cierra con una conclusión externa y no perteneciente al segundo acto. Por el contrario, esta conclusión aparece en El Barbero de Sevilla como un número musical final integrado en el acto II. La división de la estructura de la obra de Els Joglars en Acto I, Acto II y Conclusión viene dada por las tres entradas que, en Columbi Lapsus, el director da a la orquesta. Efectivamente, si en una representación de El Barbero de Sevilla, el director da la entrada a la orquesta en dos ocasiones, al inicio de la representación y al principio del segundo acto, en Columbi Lapsus un director de orquesta en patinete ante un atril y una partitura -con un claro propósito paródico-, y provisto de una batuta, aparece en tres ocasiones ante el público para dar comienzo a cada una de esas partes. Este hecho ha provocado que en nombradas ocasiones se haya hablado erróneamente de Columbi Lapsus como si se tratara de una obra estructurada en tres actos. Ahora bien, las tres entradas del director de la obra tienen dos funciones distintas: estructurar la obra para diferenciar sus dos actos, en primer lugar, e introducir la coda final con una evidente función conclusiva, en segundo lugar. De hecho, esta tercera parte de la obra no podría de modo alguno tener el rango de acto puesto que se trata de una parte que no dispone más que de una única escena, un cuadro que de hecho representa el colofón de la historia -la llegada al Vaticano del papa Juan Pablo II- y que con la obertura al primer acto -la sinfonía: que se inicia con el advenimiento del nuevo papa Juan Pablo I- cierra el círculo del corto mandato de Albino Luciani mostrando al mismo tiempo la victoria final del poder.

La segunda observación que se deduce a partir del gráfico precedente hace referencia a las diferentes piezas musicales que integran la ópera y su recuperación 
en el Columbi Lapsus. En primer lugar, se puede observar que El Barbero de Sevilla está compuesto de 51 piezas musicales. En el interior de este conjunto, las piezas se dividen en recitativos, cavatinas, canzones, duettos, arias, ariettas, tercetos, quintetos, algún número de conjunto y alguna pieza exclusivamente instrumental, lo cual no se ha especificado en el gráfico anterior. De 51 obras, Els Joglars retoma únicamente 11 para la configuración del espectáculo, piezas más representativas y conocidas de la ópera de Rossini como son el aria de Basilio La calumnia è un venticello, la cavatina de Rosina Una voce poco fa o la cavatina de Fígaro Largo al factotum por nombrar alguno de los números más famosos de El Barbero de Sevilla. De entre estas 11 piezas, no existe ningún recitativo y se ciñen en general a números cantados como las arias y cavatinas así como a alguna pieza exclusivamente instrumental. Veamos el gráfico explicativo que se muestra a continuación sobre las piezas musicales que aparecen en Columbi Lapsus:

Cuadro 3. Piezas musicales que aparecen en Columbi lapsus

\begin{tabular}{|c|c|}
\hline Sinfonía & Pieza instrumental sinfónica \\
\hline Piano, pianissimo & Introduzione: Fiorello, Conte, Coro \\
\hline Largo al factotum de la città & Cavatina: Fígaro \\
\hline Una voce росо fa & Cavatina: Rosina \\
\hline La calumnia è un venticello & Aria: Basilio \\
\hline $\begin{array}{l}\text { - Stretta del Finale I (Fermi tutti. Niun si mova) } \\
\text { - Fermi tutti. Niun si mova }\end{array}$ & $\begin{array}{l}\text { - Número de conjunto: Conte, Bartolo, } \\
\text { Rosina, Berta, Basilio, Fígaro, Coro } \\
\text { - } \quad \text { Número de conjunto: Conte, Bartolo, } \\
\text { Rosina, Berta, Basilio, Fígaro }\end{array}$ \\
\hline Pace e gloria sia con voi & Duetto: Conte, Bartolo \\
\hline Contro un cor che accende amore & Aria: Rosina \\
\hline Temporale & Pieza instrumental sinfónica \\
\hline Ah! Qual colpo & Terzetto: Rosina, Conte, Fígaro \\
\hline Di si felice innesto & $\begin{array}{l}\text { Número de conjunto: Fígaro, Berta, Barto- } \\
\text { lo, Basilio, Rosina, Conte, Coro. }\end{array}$ \\
\hline
\end{tabular}


Como se puede apreciar en el gráfico precedente, estas once piezas engloban dos piezas instrumentales sinfónicas, una introducción cantada, dos cavatinas, dos arias, dos números de conjunto, un dueto y un terceto. Éstas aparecen en el espectáculo de Els Joglars en una o en varias ocasiones en el interior de una escena o en escenas diferentes.

Por otra parte, si centramos nuestra atención en las obras musicales que aparecen en cada escena, éstas no se utilizan nunca como elemento introductor. Els Joglars sigue el modelo de la ópera e introducen cada cuadro con unos acordes arpegiados interpretados por un clavicémbalo al estilo de un recitativo. En este punto, la compañía mantiene igualmente la estructura de la ópera. Cada escena se inicia con un recitativo acompañado por un piano forte y Els Joglars retoma el modelo, aunque no se sirvan para ello de los recitativos ya existentes en la obra de Rossini y lo reduzcan de este modo a un único acorde introductor.

En tercer lugar, en el Cuadro 1 se destaca las piezas que coinciden en los dos espectáculos mostrando de forma bien visible el cambio en el orden de aparición de las mismas. En general, el orden varía de una a otra de forma bien manifiesta, sin embargo, existen dos piezas musicales que guardan exactamente el mismo orden que en la ópera de Rossini: la Sinfonía y el número de conjunto Di si felice innesto. De hecho, se trata de las dos obras musicales que enmarcan toda la ópera: el inicio y el final de la misma. El círculo se cierra de igual modo en el espectáculo de Els Joglars, esta vez adaptado a la trama de la obra teatral.

En último lugar, cabe añadir que, si bien en todas las escenas de Columbi Lapsus se hace patente la presencia de fragmentos musicales de la ópera de Rossini, la extensión de los pasajes varía de una escena a otra en función de las necesidades y de los objetivos artísticos. De este modo, nos podemos encontrar con la reproducción musical de tan sólo unos compases de una pieza o por el contrario con una reproducción íntegra de la obra en cuestión, como sería el caso de La calunnia è un venticello en la escena 4 del acto I del espectáculo.

La macro y microestructura de Columbi Lapsus está así marcada por la composición de Rossini El Barbero de Sevilla, e incluso determinada por ésta. Boadella declaraba a propósito de esta producción teatral que "la partitura impone tanto que casi se diría que siempre manda. Es, en el fondo, el triunfo de la música sobre el texto” (entrevista a Boadella en 2008).

\section{ATtO SECONDO: FUNCIONES DE LA MÚSICA EN COLUMBI LAPSUS}

Xavier Pérez, en una crítica en Espectacles Avui, apuntaba en su momento que justamente en "los acoplamientos entre la parte musical y la acción escénica, el espectador encontraría algunas de las mejores virtudes de ese montaje” (1989; traducción de la autora). En efecto, el uso de la música de Rossini en el espectáculo de Els Joglars es de una minuciosidad y precisión que recuerda el funcionamiento de “un reloj suizo” (Casas 1989). En todo momento a lo largo de la obra, la ópera está, sin excepción, ligada a la acción escénica, ya sea con un carácter puramente anecdótico o, como en la mayor parte de las veces, con una incidencia directa sobre la trama. No existe ni un solo fragmento musical en Columbi Lapsus que no tenga un objetivo preciso. Observamos, por ejemplo, que en numerosas ocasiones los personajes del 
espectáculo hablan a través de la voz y las palabras de los protagonistas del Barbero de Sevilla, produciéndose de ese modo una simbiosis entre ambos espectáculos. Así sucede, por ejemplo, al final del segundo acto, cuando dos religiosas beatas de visita en la fondazione -Vaticano- hurtan la zapatilla del Albíssimo y acaban cantando a través de la voz de Rosina el final del aria Contro un cor che accende amore: "tu mi porti a delirar", refiriéndose directamente al Albíssimo. Esta función simbiótica de la música, anecdótica en este caso, alcanza en muchas otras ocasiones una importancia capital en el desarrollo de la acción. Éste es el caso de la escena cuarta del primer acto, en la que el Honorabile Cinkus fragua una artimaña para desacreditar al Albíssimo, una calumnia que "le deje malquisto por la gente, que le presente como un hombre infame, un alma perdida”. El Honorabile hablará así a través de la voz del bajo Don Basilio con el aria La Calunnia è un venticello, la cual se escucha íntegramente a lo largo de toda la escena, cediendo su pleno significado al nuevo espectáculo. Pero, además, en esta aria se produce un crescendo -aumento progresivo de la intensidad- que Els Joglars recoge y reconvierte en recurso dramático. En efecto, el crescendo del aria se ve doblado y triplicado por la voz del guardaespaldas y por la voz estrepitosa e incluso tenebrosa del Honorabile Cinkus incidiendo directamente en la tensión dramática hasta hacerla "llegar al clímax" (entrevista a Boadella en 2008).

Por otra parte, cada escena en Columbi Lapsus acaba con un pasaje o unos pocos compases de un aria de la ópera, generalmente el final, que la concluyen. De este modo, se aprovechan las características melódicas y armónicas de la música, con un rotundo y marcado carácter conclusivo, para cerrar cada apartado. Estos finales de escena se inspiran de igual modo en las formas algo grandilocuentes de la ópera y se acompañan de una escenificación actoral operística - grandiosidad en la gestualidad y movimiento-, mostrando una vez más la magnífica labor de los actores o, como dijera Joan-Anton Benach, la "gran dosis de precisión y pulcritud interpretativas" (1989).

En Columbi Lapsus la música sirve igualmente de base para el montaje de números coreográficos bailados. Así, en una de las escenas, cuatro guardaespaldas hacen una demostración de simulacro ante el Honorabile Cinkus. Es una auténtica coreografía bailada al estilo de aquellos números de la conocida película West Side Story (Wise y Robbins 1961), en que las bandas callejeras bailaban mostrando sus atributos de fuerza y dominio con la espléndida música de Leonard Bernstein. No obstante, si en la película mencionada el carácter era grave, en Columbi Lapsus tiene un marcado carácter paródico. Este mismo procedimiento lo encontramos también en la primera escena del segundo acto, la escena del gimnasio, muestra del espíritu corrompido de la fondazione -Vaticano-. El gimnasio, situado en la obra en la antigua sede del tribunal de la Inquisición, es un lugar que desconoce el nuevo Albíssimo y cuya existencia le es ocultada. De ahí, el clima lóbrego y secreto de toda la escena, una sala de torturas y penitencias, territorio en que se procede a fortificar el cuerpo para liberar el alma, como arguye el Honorabile Matzinguer alusión directa al Cardenal Joseph Ratzinguer, quien presidió la Congregación para la Doctrina de la Fe desde 1981 hasta que en el último cónclave fuera elegido Papa, bajo el nombre de Benedicto XVI. Esta congregación, por otra parte, es la sucesora de la antigua Sagrada Congregación de la Romana y Universal Inquisición. Toda la escena está puntuada con la música de la Stretta del finale, pieza que concluye el 
final del primer acto en la ópera de El Barbero de Sevilla y que se distingue por el ritmo vertiginoso de su música en un típico crescendo rossiniano. Sobre la escena, dos bicicletas estáticas, unas pesas, unas cuerdas y cuatro personajes que sufren estoicamente todo lo que allí se les inflige. La sesión está dirigida por otro Honorabile a golpes de pitido, los cuales a su vez van marcando las diferentes etapas cada vez más mortíferas de esa sesión de purga y expiación. La sesión de gimnasia cobra una gran importancia: esos honorabiles infligiéndose duros ejercicios, elevando gradualmente la dificultad, fatigándose, y todo ello acompañado de un crescendo paulatino bajo un mismo tema repetido sin cesar, se diría casi un obstinato. Luego, de nuevo se inicia la sesión como al principio, con menor presión, coincidiendo con la reposición del tema de la partitura orquestal de la ópera. Los gestos y movimientos de todos los ejercicios de los honorables están pautados por el ritmo de la partitura, y el crescendo rossiniano queda a su vez plasmado plásticamente sobre la escena a través del propio movimiento rítmico de los actores, de esa coreografía montada a partir de la partitura, de otro ballet creado para esta secuencia entre los muchos otros ya hallados en Columbi Lapsus.

La música tiene igualmente una importancia capital en la escena segunda del acto II como flash back. En este cuadro, el bonachón Luca -el guardaespaldas- y un personaje vinculado a la KGB soviética irrumpen en la estancia del Albíssimo Master para prevenirle sobre una conspiración contra su vida y mostrarle la cara oculta de la fondazione. Disfrazado de fontanero, el Albíssimo, acompañado de estos dos personajes, efectúa un recorrido por los diferentes pasadizos secretos que comunican las estancias y otros espacios del lugar. En ese recorrido, que se revela un salto atrás en el tiempo, el espectador se encuentra nuevamente con escenas ya vividas a lo largo del espectáculo y que resumen todo lo sucedido hasta el momento. La música y los efectos especiales de sonido -eco de los pasadizos- juegan también aquí un papel primordial con la presencia de fragmentos de la ópera puestos en boca del guardaespaldas con el fin de prevenir y no ser percibidos en esa visita secreta: "Zitti, zitti, piano, piano, non facciamo confusione; per la scala del balcone, presto andiamo via di qua” o, en otra ocasión, "Piano, pianissimo, senza parlar, tutti con me, venite qua”. Observamos en esta escena, que los personajes vuelven a hablar a través de las palabras y las voces de los protagonistas de la ópera. Ahora bien, en otras ocasiones, la simbiosis que se produce entre las palabras de la ópera y su representación en la producción teatral es inversa. Este sería el caso de la última escena del primer acto. Impregnada de una gran ternura, el marco en el que se desarrolla es el jardín de la fondazione y el personaje principal el Albíssimo Master, siempre vestido de blanco, apacible, sereno y de una gran afabilidad. Ante el espectador se procede a mostrar una pintura viviente de todos sus atributos, y su sencillez y generosidad se hacen patentes a través de toda su persona: hombre de gestos suaves, dotado de una voz frágil, serena y amable, una forma de caminar dúctil y sin pretensiones. Por otra parte, la escena nos lo presenta rodeado de gente sencilla e incide en el trato particular que le concede a cada uno de ellos. A todo ello, hay que añadir un cuarto elemento que llena de magia la escena. El Albíssimo, en su descanso, se dedica a una actividad en principio de gran simpleza e incluso de un cierto infantilismo. Ayudado por la sorella Vicenza, hace "pompas de sabone”, las cuales como dice él mismo en esta secuencia "son efímeras como las ilusiones de la humanidad”, añadiendo luego "iqué frase más desafortunada!” 


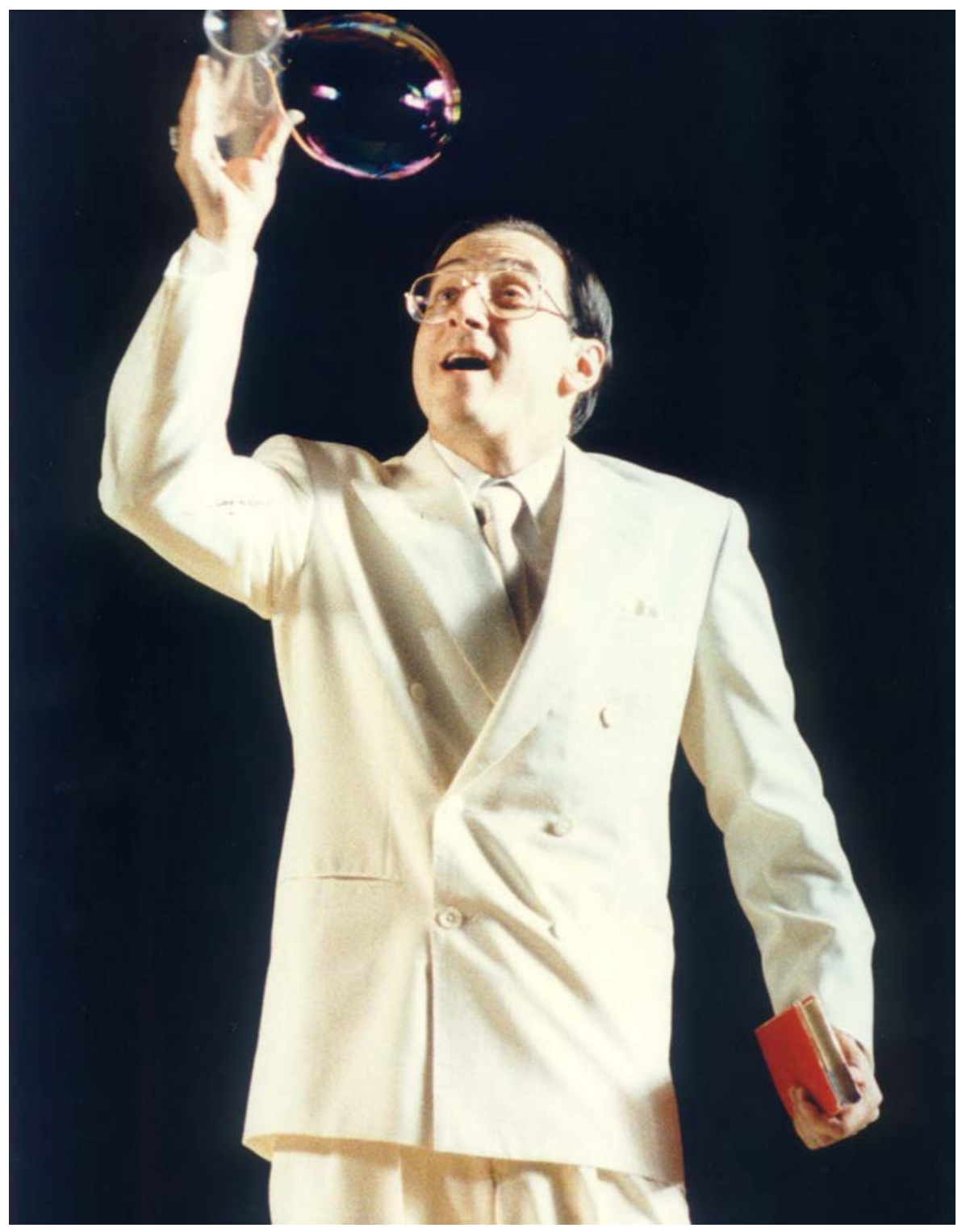

Imagen 1. El Albíssimo (Ramon Fontserè), Columbi Lapsus, 1989 (archivo de Els Joglars). 
El carácter bucólico de esta escena se ve reforzado asimismo por la música que interviene en ella. Los tres fragmentos que se escuchan pertenecen al dueto Pace e gioia sia con voi, interpretado por el bajo Don Bartolo, el anciano que desea casarse con Rosina a la fuerza, y un tenor, el Conde Almaviva. Este último se hace pasar por discípulo del maestro de música Don Basilio, argumentando que viene a reemplazarlo para poder ver a Rosina. El dueto, de carácter cómico, sobresale por la voz disimulada del Conde, quien imita el timbre y la entonación de un pobre hombre bonachón para ocultar sus intenciones y engañar así a Don Bartolo, quien por su parte desconfía de ese desconocido que quiere penetrar en su casa. Al inicio de la escena en Columbi Lapsus, aparece un único personaje, el jardinero Julián. Enciende la radio y se escuchan los primeros compases de Pace e gioia sia con voi. Luego, entra el Albíssimo y empiezan a dialogar. La música de este fragmento juega un papel esencial a la hora de crear el ambiente sosegado y templado que se respira en todo este cuadro. A ello cabe añadir, igualmente, el tono cordial en la voz de los dos personajes del dueto, una amabilidad y cortesía presentes desde el inicio de este pasaje musical. Por otra parte, el diálogo que se establece entre Don Bartolo y el Conde Almaviva se reproduce en escena. Cada intervención de estos dos personajes encuentra su correspondencia en el jardinero Julián y el Albíssimo y se corresponde con los saludos que inician cualquier encuentro:

Conde

Pace e gioia sia con voi.

Bartolo

Mille grazie, non s'incomodi.

Conde

Gioia e pace per mill'anni.

Bartolo

Obbligato in verità.

Conde

Pace e gioia sia con voi.

Bartolo

Mille grazie, non s'incomodi. (Libreto El Barbero de Sevilla, 44).

En este pasaje, la voz del bajo Don Bartolo se corresponde perfectamente con la del jardinero, algo tosco y rudo, mientras que la del Conde, reflejo de sencillez y candor, se plasma en la figura cándida del Albíssimo. No obstante, si en la ópera existe una simulación y fingimiento, en Columbi Lapsus la situación y la relación entre los personajes es absolutamente auténtica, no hay ni un átomo de hipocresía o falsedad y la voz fingida del Conde Almaviva, y motivo de burla en la ópera, encuentra todo su candor en la figura entrañable del Albíssimo.

Otra de las escenas más conmovedoras de Columbi Lapsus es la última del segundo acto. Se trata de una escena de gran gravedad, sin palabras, sólo la música del Temporale -con una función marcadamente descriptiva- que anuncia, como 
su título indica, que se avecina tormenta. Los protagonistas de la escena son tres gigantescos lienzos de Miguel Ángel que se desplazan por el escenario iluminados alternativamente por los resplandores repentinos del relámpago y de entre los cuales van surgiendo diversas manos en un intento de envenenar la taza del Albissimo. La elección de los lienzos no tiene nada de casual y simbolizan la era anterior a la caída con la imagen de uno de los ignudi, la creación de Adán, y la caída y expulsión del Paraíso, tres pinturas de la Capilla Sixtina. Luego, el Albíssimo fallece de muerte natural-manteniendo así la incógnita sobre su muerte- y se escuchan los últimos compases del Temporale, pasaje de gran intimidad gracias a la presencia de instrumentos de cuerda -violines, violas, violonchelos y contrabajos- y al uso del registro grave -violonchelo, fagot y contrabajo. Una vez que acaban las últimas notas del Temporale, empiezan a desalojar la estancia del Albíssimo. La guardia vaticana levanta al difunto llevándolo por encima de sus cabezas como si de un entierro se tratara y justo en ese momento empieza el segundo fragmento musical del cuadro. Este pasaje pertenece a la última escena de la ópera y en la partitura empieza con el Moderato Fermi tutti, niun si mova. Ahora bien, en Columbi Lapsus se reproduce únicamente el Andante, un movimiento lento en que el tempo y el carácter de la pieza coinciden perfectamente con la solemnidad de la muerte mostrada en el escenario. Pero es más, las voces de Rosina, el Conde y Bartolo explicitan verbalmente el fallecimiento del Albíssimo al cantar: "Freddo ed immobile, come una statua, fiato non restami, da respirar". Ante los ojos del espectador se reproduce lo que dictan estas breves palabras, una escena lúgubre de duelo y de muerte semejante a un cuadro barroco de Caravaggio.

Muchos otros ejemplos darían fe del papel fundamental que ejerce la música en Columbi Lapsus. Tan sólo hemos procedido a mostrar aquellos que nos parecen más significativos: bien por la inusual intrincación que se produce entre ópera y teatro en esta producción teatral, bien por el alcance dramático de algunas de sus imágenes más poéticas.

\section{CODA}

Cuando evocamos el espectáculo de Els Joglars, Columbi Lapsus, las imágenes aparecen entremezcladas: el Albíssimo, un barbero, Fígaro, Rosina... Pensamos en el Honorabile Cinkus e inmediatamente oímos a Fígaro cantar el Largo al factotum, o bien escuchamos un fragmento de la ópera y pronto acude a nosotros una imagen del espectáculo de Els Joglars. Después de Columbi Lapsus, la ópera de Rossini, El Barbero de Sevilla, estará para siempre unida a la historia del Albíssimo -el papa Juan Pablo I-, la fondazione -el Vaticano- o el Honorabile Cinkus -el cardenal Marcinkusen un espectáculo que se revela una parodia. Ahora bien, Columbi Lapsus no es tan sólo una comedia, si acaso podría hablarse de tragicomedia. En esta producción teatral conviven por igual las risas y las lágrimas, una imagen caricatural al lado de una escena espeluznante. Y la carcajada fácil que podría caracterizar a otros espectáculos de la compañía deja paso aquí a una leve sonrisa de complicidad o incluso a una mueca de disgusto. Pero Columbi Lapsus es, ante todo, una obra en forma de ópera, excepcional por su insólita utilización de la música como molde y como lenguaje expresivo, y, por lo tanto, un espectáculo de gran originalidad en su quehacer escénico y dramatúrgico. 


\section{OBRAS CITADAS}

Abellan, Joan. 2001. L'espai escènic al teatre de ELS JOGLARS (del 1962 al 2001). Bellaterra: Treball de recerca.

Alier, Roger y Gorgori, Marcel. 2002. Va de ópera. La historia de la ópera en 25 charlas. Barcelona: Vernal.

Altarriba, Dolors. 1989. «“Columbi Lapsus”, una història sobre Joan Pau I explicada pels Joglars». El 9 nou, 27 de octubre.

Arco, Antonio. 1989. "Sabor a Els Joglars”. La Verdad, 26 de noviembre.

Benach, Joan-Anton. 1989. "De Heinz Chez al Papa Luciani”. La Vanguardia, 16 de diciembre.

Boadella, Albert. 2001. Memòries d'un bufó. Madrid: Espasa Calpe, S.A.

Casas, Joan. 1989. "Senyor Boadella, vostè sí que en sap". Diari de Barcelona, 12 de noviembre.

Corral, Anna (Ed). 2011. «"El teatro es la verdad suprema”: Els Joglars, medio siglo de vida». Ínsula: Revista de Letras y Ciencias Humanas 773.

Fondevila, Santiago. 1989a. "Els Joglars: Columbi Lapsus. Albert Boadella en los sótanos del Vaticano”. El Público 75: 4-6. 1989b. "Boadella: no hemos dejado de ser cristianos”. El Público 75: 8.

.1989c. «Boadella prepara un montaje sobre el Papa Juan Pablo I titulado "Columbi Lapsus"». La Vanguardia, 7 de agosto.

Lloret Devesa, J. 1989. “Boadella serà Joan Pau I amb llibret d’òpera”. Diari de Barcelona, 24 de octubre.

Monleón, José. 1990. “Una página oscura y Els Joglars”. Diario 16, 23 de noviembre.

Pérez de Oleguer, Gonzalo. 1989. "El Vaticano de Boadella, centro de intrigas y luchas”. El Periódico, sábado 16 de diciembre.

Pérez, Xavier. 1989. Espectacles Avui, 16 de diciembre.

Ribas, Ros. 1989. «El diario de un "gorila” que acabó en opereta vaticana». El Periódico, 9-15 de diciembre.

Rossini, Gioachino. 2004. Il Barbieri di Siviglia. Milano: Ricordi.

Saumell, Mercè. 2001. Teatre Contemporani de dramatúrgia visual a Catalunya (1960-1990). Els Joglars, Els Comediants i La Fura dels Baus. Bellaterra: Tesis doctoral inscrita en el Departamento de Filología catalana. 
